\title{
Género, familia y cambio social. Ensayo sobre una entelequia
}

Isabel Marín Gómez

Universidad de Murcia

\section{Resumen}

La complejidad omnicomprensiva que presenta el estudio de fenómenos históricos como la relación entre género, familia y cambio social, pueden presentarse como una entelequia, en todos sus sentidos, desde su significado lingüístico de irrealidad al concepto filosófico aristotélico, por ello, el problema se ha estudiado con el modelo ensayístico, que permite recurrir al análisis desde la perspectiva de la Historia social, mostrando su implicación historiográfica en la emergencia de dichos fenómenos, y en la posibilidad metodológica que ofrece dicha perspectiva social de la Historia de integrar las fuentes culturales, literarias y artísticas, que permiten explicar dichos fenómenos y su contribución al conocimiento humano de los procesos de desigualdad e igualdad que afectan históricamente a las relaciones entre hombres y mujeres.

Palabras clave

Historia social; Género; Familia; Cambio social; Feminismo

Códigos JEL: B5, N01, J16, D63

\section{GENDER, FAMILY AND SOCIAL CHANGE. ESSAY ABOUT AN ENTELECHY}

Abstract

The difficulties presented by the study of the relationship between gender, family and social change, can be presented as an entelechy, in all its senses, from its linguistic meaning of unreality to the Aristotelian philosophical concept, therefore, the problem is studied with the model essayistic that allows to resort to analysis from the perspective of social history, showing its historiographic implication in the emergence of these phenomena, and in the methodological possibility offered by said social perspective of history to integrate cultural, literary and artistic aspects, which allow to explain said phenomena and their contribution to human knowledge of the processes of inequality and equality that historically affect relations between men and women.

Keywords

Social History; Gender; Family; Social Change; Feminism

JEL codes: B5, N01, J16, D63

Fecha de recepción del original: 12 de octubre de 2021; versión definitiva: 22 de diciembre de 2021.

Isabel Marín Gómez, Facultad de Trabajo Social, Departamento de Trabajo Social y Servicios Sociales, Universidad de Murcia, Edº nº 11 , Campus de Espinardo. 30100 Murcia

Tel.: +34 868888883; E-mail: isamarin@um.es; ORCID ID: https://orcid.org/0000-0002-8411-3381. 


\section{Género, familia y cambio social. Ensayo sobre una entelequia'}

Isabel Marín Gómez

Universidad de Murcia

1. Historia Social, Historia de Género, Historia de la Familia: historias paralelas

La Historia es inmanente a la condición humana, como lo es el bien y el mal. Puede parecer una obviedad, pero, quizá porque lo asumimos como atributo de la naturaleza -aunque no lo fuera-, olvidamos que lo que conmina a transitar al homo sapiens a lo largo de su proceso histórico es su relación de podercon el bien y con el mal.

En esa relación de poder, las sociedades humanas se han establecido a lo largo de la Historia organizándose jerárquicamente entre dominantes y dominados, en todas las épocas y espacios geográficos, imponiendo los primeros las reglas que determinaban quiénes estaban dentro y fuera de ellas, y aunque las jerarquías han variado en sus formas, como la raza, la casta, el estamento, la clase, o el género, construyendo y legitimando diferentes formas de desigualdad (Fontana, 1999: 167), como señala Harari, la "que ha sido de importancia suprema" entre todas ellas es "la jerarquía de género", pues "en todas partes la gente se ha dividido en hombres y mujeres. Y casi en todas partes los hombres han obtenido la mejor tajada, al menos desde la revolución agrícola" (Harari, 2014: 165).

Ese orden jerárquico basado en la división de los sexos, e históricamente sostenido, ha quedado intrínsecamente vinculado al desarrollo de las complejas relaciones entre los seres humanos, individuales y colectivas, forjando los cambios y las permanencias en el devenir de los fenómenos históricos, entre los que ha quedado secularmente implantada la institución familiar.

Por ello, pretender abordar la interconexión entre las relaciones de género, la familia y el cambio social es poco menos que una entelequia en todos sus sentidos. No es difícil asumir que desde todo punto de vista racional y emocional, dichas concepciones son por sí y entre sí fenómenos significativos que han venido afectando a todas las sociedades humanas a lo largo de la historia, y que necesitarían de una perspectiva global para ser abordadas, pero, consecuentemente, también de una amplia disección de

\footnotetext{
1 Este texto se integra y forma parte del proyecto coordinado de investigación: Entornos sociales de cambio. Nuevas solidaridades y ruptura de jerarquías (siglos XVI-XX), con referencia: HAR2017-84226-C6-1P, financiado por el Ministerio de Ciencia, Innovación y Universidades del gobierno de España.
}

los nutrientes nucleares que abonan esos conceptos generales.

Y uno de los grandes núcleos que se presenta al tener que acometer el análisis de la interrelación entre dichos fenómenos es el de la propia historia de la Historia. Como en el resto de materias del conocimiento humano, en el devenir del proceso histórico surgió la necesidad de escribir e interpretar el pasado. Una Historia que nació secularmente vinculada a la legitimación del poder, como lo estuvieron a lo largo de los siglos otras áreas del pensamiento, la ciencia, la cultura o el arte. Pero será al final de las guerras mundiales, hacia la mitad del siglo XX, cuando se entenderá la necesidad de volver a cuestionarse la idea de progreso y civilización, y por ende el pasado, como habían planteado, entre otros, Walter Benjamin (1892-1940) o Antonio Gramsci (1891-1937) frente a las barbaries de los conflictos bélicos, los exilios y los genocidios, replanteándose la condición humana, como harían desde distintas perspectivas y en diferentes momentos José Ortega y Gasset (1883-1955), Martin Heidegger (1889-1976), Hannah Arendt (19061975), Jean-Paul Sartre (1905-1980), Simone de Beauvoir (1908-1986) o María Zambrano (1904-1991), entre otros. Ideas que se hicieron más necesarias en una posguerra de la segunda guerra mundial que dio lugar a un enfrentamiento bipolar sostenido en una guerra fría que enfrentaba ideología y política comunista, con la Unión Soviética al frente, con la capitalista, liderada por Estados Unidos, cuyas repercusiones económicas, sociales y militares alcanzaron a todo el ámbito internacional.

La toma de conciencia sobre la crueldad humana y las consecuencias a las que había dado lugar no solo generaron la necesidad de proclamar una Declaración Universal de los Derechos Humanos, en 1948, suscrita en la Organización de Naciones Unidas (ONU), sino que llevaron a la Historia, como a tantas otras disciplinas, a mirarse a sí misma, y a trazar sus fundamentos éticos y científicos basándose en la búsqueda y explicación de la realidad social desde un punto de vista esencialmente objetivo, pero conscientes de la consustancial interacción del elemento subjetivo, como exponía Pierre Vilar (1997). Esto no era otra cosa que asumir la conciencia de uno mismo y de su lugar en el mundo, y para ello era necesario, como dilucidaba Vilar, "pensar históricamente", aunando el quehacer del historiador con el de su propia experiencia vital.

Seguía así, Vilar, la estela de historiadores como Marc Bloch (1886-1944), según expuso en su Apología de la historia o el oficio de historiador (1949) o de la Escuela de 
Annales $^{2}$ y de tantos historiadores que ensancharon las formas de acometer la investigación y la escritura de la Historia, especialmente desde una perspectiva "social", poniendo de relieve la necesidad de integrarla en un modelo global que abordara los ámbitos económicos, políticos, culturales y sociales, cuyas correlaciones venían determinadas por el trasfondo de desigualdad social que ha venido identificando a la humanidad desde sus orígenes.

Ello dio lugar a una multiplicidad de tendencias historiográficas -desde la microhistoria a la ecohistoria, por ejemplo, y otras muchas propuestas surgidas a partir de la segunda mitad del siglo XX-, coincidentes en la necesidad de la Historia de indagar, interpretar y explicar los grandes y pequeños problemas esenciales del pasado y del presente que afectan a los individuos y a la sociedad, para llegar a una comprensión del mundo y del escenario en el que se desenvuelve la actividad humana. El nuevo propósito de la Historia era conocer el pasado para comprender el presente y proyectar el futuro, como asentaba Fontana, entre otros historiadores, con el compromiso implícito de la necesidad de "seguir luchando por un mundo donde haya la mayor igualdad posible dentro de la mayor libertad" (Fontana, 1992: 117) ${ }^{3}$.

Se planteaba igualmente que era necesario, además, recurrir en el análisis histórico a la perspectiva interdisciplinar, e integrarla acercando la Historia a las metodologías de las Ciencias Sociales, como las de la Antropología y la Sociología, en un principio, pidiéndole a la historia, según Juan José Carreras, que en lugar de "seguir siendo la gran administradora de conceptos generales al servicio de grandes construcciones teleológicas (la modernización, la industrialización, la revolución burguesa, etc.), afinara sus sentidos para percibir lo extraño y lo marginal, lo anónimo y su sentido" (Carreras Ares, 2000: 230).

Esas perspectivas proporcionaban y posibilitaban la necesidad de acudir a otras fuentes primarias, más allá de

\footnotetext{
2 Walter Benjamin trabajó en su Tesis de filosofía de la historia o Sobre el concepto de historia en 1940, publicada póstumamente en los 50', igual que la de Marc Bloch: Apología de la historia o el oficio de historiador (1949). Benjamin se suicidó en su huida de la persecución nazi, llegando a frontera española de Portbou; Bloch fue detenido y fusilado por la Gestapo, por su pertenencia a la resistencia francesa. Gramsci será encarcelado por las milicias fascistas de Mussolini, imputado por su pertenencia al Partido Comunista, falleciendo a su salida de la cárcel, tras sufrir diversas enfermedades a lo largo de encierro. Bloch y Lucien Febvre (1878-1956) fundaron en 1929 la revista francesa Annales d'histoire économique et sociale, implantando una nueva corriente historiográfica alejada del acontecimiento político y el protagonismo del individuo representativo frente a los procesos sociales, incluyendo un acercamiento a las metodologías de las ciencias sociales. Líneas que vieron interrumpidas por la segunda guerra mundial, retomadas con la tesis de Ferdinand Braudel, El Mediterráneo y el mundo mediterráneo en la época de Felipe Il, defendida en 1947, cambiando la visión del tiempo histórico hacía la idea de la historia global, y dando lugar al desarrollo de la pluralidad de tendencias historiográficas, con mayor relevancia de la Historia Social.

3 En España tuvo un gran empuje la Historia Social, y muchos historiadores, como Fontana, analizaron la situación de la historiografía española, siguiendo las propuestas de Pierre Vilar; E.P. Thompson o Eric Hobsbawm, entre otros, creándose, por ejemplo, en 1987 el Instituto de Historia Social-en la Universidad de Educación a Distancia (UNED)- convertido desde 1994 en Fundación Instituto de Historia Social, publicando desde 1987 la revista Historia Social. Además, a partir de esos años aparecen numerosos estudios como: Santiago Castillo (coord.) (1990): La historia social en España. Actualidad y perspectivas, Madrid, Asociación de Historia Social-Siglo XXI de España, o Julián Casanova (1991), La historia social y los historiadores, Barcelona, Crítica. Pasado casi un cuarto del siglo XXI, se puede afirmar que perspectiva social en la interpretación de la Historia ha quedado plenamente integrada en el análisis y la escritura de la Historia.
}

los documentos oficiales, que hasta entonces habían sido la referencia principal para determinar el dato histórico. Fuentes que la humanidad ha ido desarrollando a través de diversas formas de expresión individual y social: desde la pintura a la hemerografía, desde la literatura a la fotografía, el cine, o el testimonio oral, entre otras, que coadyuvaban a análisis más complejos e interpretaciones más completas, y a la comprensión del sentido histórico de la humanidad y su cohabitación entre lo racional y lo emocional. Se reconocía así la "utilidad social" de la Historia, valorada como toda actividad humana "por el servicio que rinden al conjunto" de la humanidad, según Fontana (1992), adquiriendo mayor relevancia en tanto que:

"De entre las ciencias sociales, la historia tiene el privilegio de ser la que mayores servicios puede rendir, porque es la más próxima a la vida cotidiana y la única que abarca lo humano en su totalidad. Sin olvidar tampoco que, cuando se lo propone, resulta ser la más inteligible para un mayor número de receptores de su mensaje estudiantes, lectores o espectadores-. No importa que ello la haga más arriesgada; que no permita adornarla con unas apariencias de exactitud que hoy sabemos, además, que no son un criterio de validez científica, sino una mera ilusión" (Fontana, 1992: pp. 145-146).

Precisamente, para la historiografía española también Fontana abordaba esa revisión ética y científica de la Historia en los 90' del siglo XX, a partir de la dimensión que adquirió la idea "finalista" que proliferó a finales de los 80', cuando en el verano de 1989, previo a la caída del Muro de Berlín en noviembre de ese año, se publicó el ensayo del entonces desconocido politólogo estadounidense Francis Fukuyama (Chicago, 1952), titulado "The End of History?"4, despertando reacciones internacionales de todo tipo, de las más afines a las más opuestas, y desde todos los ámbitos del conocimiento académico, científico y de la comunicación; llevando a Fukuyama a reafirmarse en sus tesis en un libro: The end of the History and the last man (1992) en el que, pasando por viejas interpretaciones de Hegel, Kojève, Kant y Nietzche, argumentaba una expansión mundial del capitalismo y de la democracia liberal que finiquitaba la evolución ideológica de la humanidad, y por ende la Historia -en sentido hegeliano-, diseñando una nueva era posthistórica preeminentemente neoconservadora. Al menos eso era lo que pretendía difundir desde su ideología política, especialmente "interesada en ensalzar los valores del sistema económico capitalista y "aniquilar" al enemigo comunista" (Sanmartin, 1998: 236).

En todo caso, el hecho de que un texto bastante "mediocre" tuviera tanto éxito se debía a la deliberada promoción del conservadurismo estadounidense para rentabilizar la desintegración de la Unión Soviética (Fontana, 1992) y también al momento de desconcierto en el que se veía

\footnotetext{
4 El ensayo fue publicado por The National Interest, 16 (1989), pp. 3-18; y en España en 1990, por la revista: Claves de la razón práctica, 1, pp. 85-96, con el título "¿El fin de la Historia?".

5 El libro fue publicado en España ese mismo año de 1992, con el título: El fin de la Historia y el último hombre, por Planeta. Sobre la evolución de las tesis de Fukuyama hasta 1998, véase Sanmartin (1998).
} 
inmerso el conocimiento científico, como el resto de ámbitos sociales y culturales, ante "un periodo de rupturas, de fracturas, de recomposición general de las fuerzas geoestratégicas, de las formas sociales, de los autores económicos y de las referencias culturales" (Ramonet, 1997: 15), que, no obstante, con la caída del Muro de Berlín como punto de inflexión, adquiría conciencia de la situación de incertidumbre frente al proceso de globalización, en el que los extraordinarios avances tecnológicos en la comunicación y en el concepto de mercado influían decisivamente en los cambios pluridimensionales.

Es necesario conocer y comprender estos contextos de evolución, desconcierto e incertidumbre que supuso el cambio desde las guerras mundiales hacía el impulso del modelo neoliberal del final del siglo XX -la llamada postmodernidad-, porque es en ellos en los que el pensamiento, la ciencia y la tecnología se transformaban de manera consciente, incluida la propia disciplina de la Historia, al mismo tiempo que el proceso histórico en el que se integraron y desenvolvieron; pero, sobre todo, porque son los que van a propiciar que aparezca e intente consolidarse la cuestión de género, especialmente vinculada a la historia de las mujeres, y, más aún, porque van a tener que ser las propias mujeres las que, una vez más, aborden la cuestión femenina, y tanto desde el activismo y del compromiso personal y político, a través del movimiento feminista, como desde el pensamiento humanístico y científico, porque, también una vez más, habían sido excluidas de todos esos procesos.

Esos grandes cambios que se producen en la historiografía en la segunda mitad del siglo XX, encaminados especialmente a conformar una Historia Social, muy necesaria sobre todo para la revisión y reinterpretación de la Historia contemporánea, estarán liderados por hombres, esencialmente europeos y, en general, de tendencias marxistas: Marc Bloch; Lucien Fevre; Fernand Braudel; Giovanni Levi; Carlo Ginzburg; Emilio Gentile; Eric Hobsbawm; E. H. Thompson; Haiden White o Reinhart Kosellec. En España, y más tardíamente por la dictadura franquista, historiadores como Tuñón de Lara; Josep Fontana; Santos Juliá; Miguel Artola; Juan José Carreras; Julián Casanova; Juan Pablo Fusi; Eduardo González Calleja; Ramón Villares; Enrique Moradiellos; Manuel Pérez Ledesma; o hispanistas como Paul Preston; Hug Thomas; Rymond Carr o lan Gibson, abordarán problemas historiográficos y acontecimientos históricos contemporáneos, así como los fenómenos que se derivaron de ellos, sin duda, necesarios e imprescindibles en esos momentos, pero no contemplaban en sus análisis la condición femenina ni como sujeto histórico ni como objeto de su estudio.

Es por ello que un buen número de mujeres, pensadoras e intelectuales de diferentes disciplinas, así como activistas del feminismo de las más diversas tendencias, retomarán la cuestión femenina a partir de los años $60^{\prime}$ del siglo XX, de manera paralela a ese proceso historiográfico, y serán ellas las que tengan que teorizar, interpretar, reescribir y descubrir nuevas cuestiones en las que las mujeres eran objeto de estudio, investigación y también de reivindicación, para tratar de visibilizar el inmenso vacío de conocimiento que le venía afectando desde el pasado y las condiciones de desigualdad y discriminación que seguían afectándole en el presente. Según Rose: "la historia de género se desarrolló en respuesta a la investigación y a los debates sobre la historia de las mujeres. La historia de las mujeres comenzó a retoñar como un campo de estudio en los últimos años sesenta y floreció en los setenta, continuando hasta la actualidad como un componente fundamental de la historia de género" (Rose, 2012: 19).

Las historiadoras se vieron abocadas, más que a formular una tendencia historiográfica por sí misma, a especializarse en rescatar las numerosas cuestiones y problemas que afectaban a las mujeres desde el pasado y que habían sido omitidas, así como las numerosas acciones que habían sido llevadas a cabo por mujeres y que eran absolutamente desconocidas. En 1992, y al hilo del citado debate sobre el fin de la historia, Fontana reconocía que "uno de los campos de más rápido crecimiento en los últimos años ha sido la de la historia de las mujeres, que ya se ha transformado, antes de consolidarse, en la gender history, que pretende ir más allá de la consideración aislada de la mujer" (Fontana, 1992: 83).

Según Rose (2012), la profesión de historiadoras e investigadoras de la historia tuvo diversa proyección internacional dependiendo de las culturas institucionales, en la medida que tuvieron apoyos más o menos tempranos. Parece que fueron más rápidas las iniciativas en Estados Unidos, donde ese apoyo se inició en algunas universidades hacía la década de 1970, aunque muchas de ellas tuvieron que escribir historia de las mujeres al margen de la academia e inspiradas por el movimiento feminista. En 1977 se publicaba en Boston: Becoming visible: Women in European History, editada por Renate Bridenthal y Claudia Koonz, historiadoras europeas afincadas en EEUU, en la que recogían la historia de las mujeres desde el antiguo Egipto hasta la posguerra mundial a través de diversos ensayos, afirmando que la pretensión de la obra era "tanto restituir a las mujeres a la historia como explorar el significado de la singular experiencia histórica de las mujeres" (Rose, 2012: 22-23).

También en Europa proliferaron revistas científicas de Historia que se arriesgaron, según Gisela Bock, a "dar el paso de dedicar algunos números tanto a la historia de las mujeres como a una nueva generación de historiadoras", poniendo al descubierto la emergencia de la historia de las mujeres en los 70' y 80', así como "la existencia de una larga tradición de historiadoras" que habían "orientado su estudio hacia ese campo, una tradición que las instituciones académicas de esta profesión habían borrado o relegado a un segundo plano" (Bock, 1991: 55-56).

Así salieron a la luz la "diversidad de experiencias y situaciones femeninas", consecuencia de que la historia de las mujeres había tenido que "abordar virtualmente todos los dominios de la sociedad", desde los ámbitos en los que tenía presencia la mujer, tanto en los que eran una mayoría como en los que eran una minoría, o"los que igualaban en número a los hombres: las familias, las relaciones sexuales, las clases, las minorías étnicas" (Bock, 1991: 57).

En efecto, en ese mismo contexto había surgido con fuerza la revisión histórica de los grandes "procesos de cambio social en la familia y la sociedad", inspirados, igualmente desde los 70' del siglo XX, por la "unión entre la demografía histórica con la -entonces- nueva historia social" 
abriendo "dos vías de investigación que han renovado por completo los objetivos explicativos de la evolución y procesos de cambio o/y resistencias de las sociedades" desde el siglo XVIII al XXI, revisando "Ios modos de vida de la población y que ésta, a través de las familias," se convirtiera "en sujeto del cambio social" (Chacón Jiménez, 2020: 32).

No obstante, además de las aportaciones pioneras de historiadoras como Natalie Z. Davis, Joan Kelly y Joan W. Scott "que invitaban al análisis histórico de las relaciones de género, superador de las mujeres como objeto de estudio, los estudios históricos sobre las construcciones de feminidades y de masculinidades", que "no han dejado de proliferar" (Blasco Herranz, 2020: 150), fue la historiadora Gerda Lerner (1920-2013) quien introdujo un aspecto transcendental no solo para la Historia de género y de la familia, sino también para el desarrollo de las teorías feministas: el patriarcado. La relevancia de su aportación se debió, sobre todo, a que situaba el origen del patriarcado "en una construcción social, no en un condicionamiento natural; por tanto, si se trataba de algo que había sido creado, podía ser, a su vez, cambiado y rechazado. El patriarcado no era algo permanente" (Medina Quintana, 2014: 225).

Gerda Lerner, de origen austriaco, militante comunista, logró escapar de la persecución nazi en 1938 y exiliarse en EEUU, donde, tras varios empleos domésticos, y sufrir el acoso macartista junto a su marido, Carl Lerner, director teatral, en cuyas producciones colaboraba, se doctoró en la Universidad de Columbia en 1966 con una tesis sobre las hermanas abolicionistas Sara y Angelina Grimke. Involucrada en diversos movimientos sociales, reivindicando mejoras en el sistema púbico educativo, y participando en protestas contra las armas nucleares, Lerner siguió con sus investigaciones feministas e inició su docencia sobre Historia en el Sarah Lawrence College de Nueva York, creando el primer Programa de Posgrado en Historia de la Mujeren Estados Unidos en 1972 (Medina Quintana, 2014)

Como Lerner explicaba en la introducción a su obra La creación del Patriarcado, publicada en EEUU en 1985 -única traducida y publicada en España en 1990-, había tardado ocho años en escribirlo, desde que en 1977 empezó a plantearse las preguntas que le llevaron a formular "la hipótesis de que la relación de las mujeres con la historia es lo que explica la subordinación femenina, las causas de la cooperación de las mujeres en el proceso de su propia subordinación, las condiciones para oponerse a aquélla, y el nacimiento de la conciencia feminista" (Lerner, 1990: 9). Lerner analizaba cómo los estados arcaicos se habían organizado "sobre la base de la familia patriarcal y aprendieron a someter a otros pueblos gracias a la práctica de someter a sus propias mujeres, culminada con la institucionalización de la esclavitud, que habría empezado por la esclavización de las mujeres de los pueblos vencidos" (Fontana, 1999: 168).

La historiadora alemana Gisela Bock (1991), cuyo artículo fue publicado en Gender \& History (vol. 1 - no 1) de $1989^{7}$, analizaba los diferentes aspectos del debate sobre

\footnotetext{
6 Véase también Almisas Albéndiz, Manuel: “Gerda Lerner, feminista e historiadora injustamente olvidada", Rebelión, 07/03/2013. https://rebelion.org/gerdalerner-feminista-e-historiadora-injustamente-olvidada/.

7 La publicación de este artículo en español se hizo, como se cita en la biblio-
}

Historia de las Mujeres e Historia de Género, reconociendo sus dimensiones internacionales. Bock relacionaba los aspectos referidos a las numerosas categorías de análisis surgidas en torno a la cuestión femenina en el campo disciplinar de la Historia, atendiendo a las posiciones originadas respecto al género como categoría social, cultural e histórica, así como al problema sexual y biológico que se derivaba de los enfoques heterogéneos. Igualmente, Bock planteaba la necesidad de "pensar en relaciones", puesto que "el género o los sexos" no se referían "a uno varios fenómenos concretos", sino que aludían "a un conjunto complejo de relaciones y procesos" (Bock, 1991: 68) que afectaban igualmente a la determinación de la Historia de género, a la Historia de las mujeres o a la Historia de los hombres, así como a la propia relación con la Historia social, en la que había que reconsiderar los análisis de las clases sociales y las relaciones de género, y éstas con otras relaciones socioculturales como, por ejemplo, "la raza, la edad, la sexualidad, la cultura, el lenguaje, la libertad, la religión, la familia, la economía" (Bock, 1991: 75).

Así, pues, la década de los 90' fue prolífica para generar los grandes cambios que experimentó la disciplina histórica y constatar la necesidad de una restitución de "las mujeres a la historia" y "restituir la historia a las mujeres" (Bock, 1991: 56), acometiendo esa gran complejidad de fenómenos históricos que afectaban al ámbito femenino, y que dieron lugar a una amplia historiografía en todo el ámbito occidental.

En Europa se va a visibilizar en la edición de una ambiciosa colección francesa: L'Histoire des Femmes en Occident, dirigida por el historiador George Duby (1919-1996) y la historiadora Michelle Perrot (1928-), publicada en 19901992. Perrot explicaba la experiencia sobre la gestación y realización de la obra, así como los debates a los que había dado lugar su publicación, en un artículo publicado en la revista Ayer, en 1995, en el que, como otras historiadoras, incidía en la necesidad de abordar la historia desde la perspectiva de género y visibilizar los problemas silenciados de las mujeres.

Igualmente, Perrot insistía en la importancia que tenían esos estudios para que se produjera un verdadero cambio en la propia historiografía, así como en investigar la realidad social, analizando, interpretando y exponiendo la relevancia que había tenido el desarrollo de una historia de la familia, que abarcaba mucho más que los aspectos habituales, integrando las aportaciones de las mujeres a los cambios que habían experimentado los modelos de familia tradicionales (Perrot, 1995; Bel Bravo, 2000).

Como resultado del arduo trabajo de las investigadoras se logró también que, a lo largo de los 90', se propiciaran para historiadoras e investigadoras en otras disciplinas científicas, algunos reconocimientos institucionales de los estudios de género en parte del ámbito internacional oc-

grafía, en el número 9 de la revista Historia Social (1991), traducido por Marisa Ferrandis Garrayo (p. 77). La revista Gender \& History fue fundada en 1989 bajo la edición de Leonore Davidoff (1932-2014), socióloga, historiadora, ensayista y feministas estadounidense, que desarrolló su trabajo de investigación sobre la historia social y la historia de las mujeres en la Universidad de Essex (Reino Unido), a donde se trasladó en 1968. Gender \& History 25th Year Virtual Issue (2013): https://onlinelibrary.wiley.com/page/journal/14680424/homepage/ gender_history_25yr_virtual_issue.htm 
cidental, y esencialmente en el académico y científico de la Investigación, Desarrollo e Innovación de las Universidades.

Además, las historiadoras aprovecharon las propuestas epistemológicas y metodológicas de la Historia Social, que, junto con el reconocimiento de la amplitud panorámica que permitía la interdisciplinariedad, integraba las llamadas "nuevas" fuentes para la Historia, anteriormente referidas, para encontrar respuestas a la multitud de interrogantes que planteaban las desconocidas cuestiones femeninas. Desde el reconocimiento de las reivindicaciones por los derechos de la mujer de ilustradas como Olimpia de Gougues o Mary Wollstonecraft a otras filósofas, escritoras, pintoras, científicas, que desde la Antigüedad Clásica al siglo XX habían desarrollado importantes e influyentes trabajos en sus respectivos ámbitos del conocimiento humanístico, artístico y científico.

Así fue también en el caso de España, con la constitución en 1991 de la Asociación Española de Investigación de Historia de las Mujeres (AEIHM), por historiadoras como Cándida Martínez López, Mary Nash o Reyna Pastor, cuya actividad investigadora llevará a la fundación de la Revista Arenal-Revista de Historia de las Mujeres, en 1994, en la Universidad de Granada.

Relevante fue también en España, sobre todo para las investigaciones de la Historia del siglo XX, la repercusión que tuvo la introducción de las fuentes orales en los $80^{\prime}$ y 90', con los trabajos pioneros de María Carmen García-Nieto (1928-1997), abriendo un gran campo para el estudio de las mujeres, pues tener de primera mano los testimonios de vida posibilitaba alcanzar un conocimiento mucho más amplio sobre lo que hasta entonces había sido "marginal" y "anónimo" como ponía de manifiesto Carreras (2000: 230), frente a la documentación oficial, en la que si ya era de por sí complicado conocer los entresijos que llevaban a su emisión, mucho más difícil era encontrar referencias sobre las problemáticas femeninas.

Las contribuciones a los estudios de género y de las mujeres se extendieron cuantitativa y cualitativamente de manera extraordinaria y global, desde los 90', llevando implícita la consolidación de la concienciación femenina para la que, sin duda, había sido imprescindible la reactivación de los movimientos feministas desde la década de 1960, y a ese proceso se unió igualmente, de manera paralela, la historiografía de la Historia de la Familia, consciente del papel que representaba la mujer en los cambios que venía experimentando el modelo tradicional de familia, como ha demostrado una elevada proliferación de estudios e investigaciones (Bel Bravo, 2000; Vázquez de Prada, 2008), que, como señala Chacón, han reconocido la necesidad de considerar la interdisciplinariedad en el estudio y análisis de la familia, así como la comprensión de que las realidades cotidianas son el resultado de "un proceso histórico caracterizado y definido por esta compleja, diversa, plural y multicausal realidad" (Chacón Jiménez, 2020: 33), y, como afirma Chacón, "si la categoría historiográfica mujer ha revisado y replanteado los significados del proceso histórico" que se estudia, "el de la familia ha ocupado dicha temporalidad por la amplitud de realidades que explica y refleja, tanto en procesos individuales de biografías y ciclos de vida como de redes de relación social" (Chacón Jiménez, 2020: 45).
Entre las tendencias historiográficas del siglo XXI, la introducción del estudio de las emociones en la Historia abre más posibilidades para el conocimiento "del significado que los seres humanos han dado al mundo social" $y$ "la valoración del cuerpo como forma de acceso al mundo, como dador de ese significado" (Díaz Freire, 2015: 13), y especialmente de las mujeres, cuyo vínculo emocional con el mundo le ha sido adjudicado históricamente, y quizá pueda ser provechoso para su propio conocimiento y el de la humanidad, pero, pese a todos estos avances, abordar la cuestión de género no ha dejado de ser problemática, como vemos a través del análisis científico, cultural y social que se refiere a continuación.

2. La cuestión de género en el paraíso de los pasos perdidos

El escenario que se abre cuando se afronta el estudio de la cuestión de género podría responder a aquella imagen que muestra la obra La vida es sueño(1636), en la que Calderón de la Barca fabula en boca de Rosaura, una de sus protagonistas, reflexionando sobre el sabio mísero y pobre "que solo se sustentaba de unas hierbas que cogía./¿Habrá otro, entre sí decía, más pobre y triste que yo?;/ y cuando el rostro volvió halló la respuesta,/ viendo que otro sabio iba cogiendo las hierbas que él arrojó". Y es que, sea cual sea la perspectiva desde la que se aborde, el género se presenta como una materia tan sumamente compleja que los imperativos académicos y científicos se diversifican y nos obligan a mirar atrás y alrededor para recoger esas "hierbas" arrojadas sin saber muy bien cómo masticarlas y digerirlas.

Desde que en los 60' del siglo XX apareciera el concepto género como objeto de investigación, análisis y estudio, quedó patente la transversalidad y la interdisciplinariedad que le afectaba y requería para su comprensión e interpretación. No solo eso, además, pocos objetos de estudio como el de género han propiciado tantos debates y controversias, y han quedado permanentes. Como señala Blasco, dada la "multiplicación de estudios, temas y enfoques referidos a diferentes periodos históricos y distintos espacios geográficos resulta prácticamente imposible ofrecer un estado de cuestión omnicomprensivo" (Blasco Herranz, 2020: 145)

Es difícil, pues, establecer unos marcos epistemológicos y metodológicos únicos y bien definidos, como es complicado situar su aparición en un tiempo histórico. Al igual que ocurre con el estudio de los conceptos feminismo y feminista, no denominados así hasta finales del siglo XIX, pero se observó que la conciencia y la necesidad de reconocimiento y actuación de las mujeres respecto a su condición había estado presente desde siglos anteriores, la cuestión género, como estatus que diferencia a hombres y mujeres y establece sus posiciones entre sí y con el resto de la sociedad, se retrotrae a tiempos lejanos e indefinidos, posiblemente a los inicios primitivos de la construcción 
social del ser humano, cuando empieza a organizarse y a establecerse ese citado orden jerárquico en el que mujeres y hombres van a ocupar niveles distintos, posicionándose el hombre en un nivel superior al de la mujer, coincidiendo en la practica totalidad de las culturas orientales y occidentales, viéndose especialmente afectada, además, por la configuración de la familia como agente nuclear de la organización social.

En el caso de Occidente, las evidencias escritas de la exclusión de las mujeres de la esfera pública remiten a casi tres mil años atrás, como ha mostrado la historiadora Mary Beard destacando de La Odisea de Homero el momento en el que Penélope es recriminada por su hijo, Telémaco, para que se retire a sus habitaciones y deje al "cuidado de los hombres" el "gobierno de la casa" (Beard, 2018: 15-16). Condena al silencio femenino que no era solo una referencia ficticia, porque las realidades sociales gestadas durante la Antigüedad Clásica y tras ella, con una Edad Media en Europa de hegemonía católica, consolidaron en el sistema estamental el modelo de familia, sobre todo para las clases privilegiadas, bajo la fórmula de contrato matrimonial de dominación masculina, en el que la mujer, además de la aportación obligada de la dote, era el objeto necesario para la procreación y continuidad de los lazos de sangre y, consecuentemente, la ampliación y transmisión patrimonial a través del linaje y la herencia (Bel Bravo, 2000).

El ascenso de las clases burguesas en la sociedad mercantil de la Edad Moderna no hará más que imitar y reproducir los privilegios medievales, reforzando las responsabilidades de la mujer en cuanto a la preservación de su virginidad y pureza para el matrimonio, la de la maternidad y la del sostenimiento de la fidelidad y moral respecto al marido a lo largo de toda la vida marital, extendiéndola incluso a la viudedad. Los vínculos matrimoniales, el hogar, la descendencia, serán sagrados, como mostraba la iconografía del pintor flamenco Jan van Eyck, en el Retrato de Giovanni Arnolfini y su esposa (1434).

Un modelo extraordinariamente extendido en el siglo $\mathrm{XVI}$, con la expansión occidental en América, la Reforma luterana y la Contrarreforma católica. La sagrada familia se convertía en un tema recurrente y referente en la vida cotidiana, como reflejaba la pintura. Desde Miguel Ángel en su Tondo Doni (1508) al Greco en su Sagrada Familia (1595), o Durero en su Adoración de los magos (1504), prefiguraban el ideal que se trasladaba a los retratos de familias burguesas, y que fueron encargados a relevantes pintores y pintoras de cada época, siendo incluso tema imprescindible para los artistas y su familia. Con sus retratos familiares refrendaban el estatus de la estirpe representada, a semejanza de los que contribuían a legitimar a las familias aristocráticas y monárquicas. Ejemplos como Retrato de familia (1583) de Key Adriaen Thomas; La familia del pintor (1622) de Jacques Jordaens, o Las Meninas (1656) de Velázquez, representando a la familia de Felipe IV, o La Familia de Carlos IV (1800) de Goya, no han dejado de reproducirse en el Arte a lo largo de la historia.

Los grandes cambios económicos que propició el imperialismo colonial en los siglos XVII y XVIII se tradujeron en Europa en un proceso industrializador imparable liderado por Inglaterra, paralelamente al desarrollo de una sociedad que, pese a ser más ecléctica por la diversificación reli- giosa y una considerable expansión de los conocimientos científicos e ilustrados, mantenía la jerarquía de género, asignando roles en la medida que construía un espacio público, ocupado por el hombre, y lo diferenciaba del espacio privado y doméstico, asignado a la mujer. Así lo muestra Luis Vélez de Guevara en su relato El diablo cojuelo (1641), en el que el personaje de tradición popular llevará al estudiante don Cleofás, como curiosos paparazzi e incluso voyeurs, a observar bajo los tejados de Madrid las actitudes individuales y sociales que identifican la moral de la época, especialmente la matrimonial y familiar, como hará la versión francesa Le Diable boiteux (1707 -revisada en 1726) de Alain-René Lesage. Con casi un siglo de diferencia, ambas versiones presentaban una crítica social, y aunque la española contenía una finalidad humorística, la de Lasage, en plena ilustración francesa, no se deshacía de "intenciones moralizantes marcadas por una misoginia que se nutre de las obsesiones personales de un padre de familia", presentando un "espíritu limitado y pequeño burgués, que recurre con facilidad a tópicos y clichés para responsabilizar al género femenino de las costumbres de la Regencia en materia de moral sexual y ensalzar, indirectamente, la felicidad matrimonial" (Reboul, 1996: 242).

Esa visibilidad de las desigualdades entre hombres y mujeres venía siendo objeto de debate en los ámbitos intelectuales de la Europa Moderna. En 1673, en la Francia de Luis XIV -el Rey Sol-, François Poulain de La Barre (16471725) publicó De l'égalité des deux sexes, discours physique et moral où l'on voit l'importance de se défaire des préjugez, reclamando una educación para la mujeres, cuya inteligencia y capacidades equiparaba a las de los hombres, considerando que la meta de ambos era alcanzar la sabiduría para "desarrollarse íntegramente como seres humanos" (Amorós Puente, 2018: 34), ideas de escasa repercusión social. Al contrario, un siglo después, en la Francia ilustrada, se asumirán e impondrán socialmente propuestas como la de Jean-Jacques Rousseau (1712-1778) en Emilio o De la educación (1762), el tratado para educar al "ciudadano ideal", en el que establecía que "la educación de las mujeres debe estar en relación con la de los hombres", y define el papel de la mujer respecto a los hombres en el matrimonio y en la sociedad, destinada a:

"Agradarles, serles útiles, hacerse amar y honrar por
ellos, educarlos cuando niños, cuidarlos cuando mayo-
res, aconsejarlos, consolarlos, hacerles grata y suave la
vida son las obligaciones de las mujeres en todos los
tiempos, y esto es lo que desde su niñez se las debe
enseñar. En tanto no alcancemos este principio, nos
desviaremos de la meta, y todos los preceptos que les
demos no servirán de ningún provecho para su felici-
dad ni para la nuestra" ${ }^{8}$.

El ideal de Rousseau se ajustaba al modelo de familia y de mujer de las clases sociales burguesas y su proyecto industrial y capitalista, que iba dominando en la sociedad

\footnotetext{
${ }^{8}$ Versión de la obra de Jean-Jacques Rousseau (1762), Emilio o De la Educación, publicada por textos.info. Biblioteca digital abierta, p. 399, accesible en: https:// www.textos.info/jean-jacques-rousseau/emilio-o-de-la-educacion/descargarpdf.
} 
europea, subrayado por la ruptura con el Antiguo Régimen y su máxima expresión con la Revolución francesa de 1789. La conquista de los ámbitos económicos les permitió ocupar definitivamente los espacios políticos, expresamente adjudicados a los hombres. Con ello, no solo persistían las desigualdades sociales que conformaban las nuevas estructuras sociales (Pontón, 2016), sino la discriminación estructural que afectaba a la mujer por su condición femenina.

Algunas voces se manifestaron frente a esta desigualdad, reclamaron derechos y propusieron soluciones, como Nicolás de Condorcet en Sobre la admisión de las mujeres al derecho ciudadano, de 1790; Olympe de Gouges en la Declaración de los Derechos de la Mujer y de la Ciudadana, de 1791, ambos publicados en Francia; Josefa Amar y Borbón en Discurso sobre la educación física y moral de las mujeres, publicado en España en 1790, o Mary Wollstonecraft en Vindicación de los derechos de la mujer, publicado en Inglaterra en 1792, poniendo de relieve las grandes diferencias que afectaban a las mujeres frente a los hombres y la vulneración de derechos que esa desigualdad suponía para ellas.

Pero, lejos de aceptar, asumir e implantar un modelo de equidad en derechos y libertades entre los sexos, las diferencias se ampliaron y consolidaron, al igual que entre las clases sociales. Limitar y prohibir los espacios de poder a las mujeres se adecuaba extraordinariamente a reforzar el poder masculino en unas clases burguesas que alcanzaban mayor representatividad y dominación económica y política, y ello llevaba consigo establecer unas normas morales que controlaran igualmente los ámbitos sociales y culturales, más propicios para despertar conciencias sobre las situaciones de desigualdad, discriminación o exclusión. La oportunidad que ofrecían los presupuestos de igualdad, libertad y fraternidad que planteaba el pensamiento ilustrado, y que la Revolución francesa llevó entre sus proclamas, no llegó a ser un verdadero "movimiento original y unitario, paneuropeo, destructor del cristianismo, padre de la democracia, defensor de la igualdad" ni "redentor de los oprimidos" (Pontón, 2016: 670).

$Y$ mucho menos de las mujeres, que fueron identificadas con la "oscuridad" frente a las "luces de la Razón", que representaba la identidad masculina. Así lo simbolizaba en la música Wolfgang Amadeus Mozart (1756-1791), que en La flauta mágica (1791) plantea el conflicto de poder entre Sarastro, personificando el ideal de la Razón, frente a la Reina de la Noche, que representa las tinieblas, convirtiéndose "subsidiariamente" en el "conflicto de la masculinidad con la femineidad", y atribuye a la mujer el papel de "mala madre que, para reconquistar su poder, está dispuesta a sacrificar su hija y entregarla al abominable Monostatos" (Starobinsky, 1988: 126). Más aún, la feminidad se ensombrece en la persona de la Reina para dar protagonismo a su hija Pamina, enamorada y entregada a su amor, Tamino, con entera "sumisión a la ley iniciática, que es un imperativo masculino. La mujer será acogida en la persona de Pamina rechazada, arrojada al abismo en la persona de la Reina y de sus secuaces. La joven pareja termina por reconciliarse; pero parece ser que la viuda tenebrosa, la bruja de vocalizaciones sublimes, desaparece para siempre" (Starobinsky, 1988: 127).
Condenadas a la oscuridad, las mujeres que entran en la Edad Contemporánea del siglo XIX la llevarán impuesta por los cambios sociales y culturales que se estaban experimentando, y que retrataba en la literatura Honoré de Balzac (1799-1850), en sus Estudios de mujer (1830), diferenciando entre la mujer aristócrata y la burguesa. Para Balzac, las mujeres aristócratas que habían fundado salones de nivel europeo, habían impuesto opiniones, superando incluso a artistas y pensadores, también habían "cometido el error de abandonar el terreno, abochornadas por tener que luchar contra una burguesía ebria de poder que quizá haya irrumpido en el escenario social para que la hagan picadillo los bárbaros que la acosan. Así, donde los burgueses pretenden ver princesas, solo vemos a chicas como Dios manda" (Balzac, 2010: 78), y en cuanto a la mujer burguesa, Balzac decía que era "imposible confundirla" con esa "señora como Dios manda"; y no eran comparables porque:

"La burguesa es hacendosa, sale a la calle haga el tiempo que haga, corretea, va y viene, rebusca con la mirada, vacila antes de e entrar en una tienda. Ahí donde la mujer como Dios manda sabe lo que quiere y lo que hace, la burguesa es indecisa, se remanga el vestido para cruzar el arroyo, lleva a rastras a un niño que la obliga a estar pendiente de los coches, es madre en público y charla con su hija, lleva dinero encima y calza medias de día, lleva una boa sobre una esclavina de piel de invierno, chal y bufanda en verano: la burguesa asume de maravilla los pleonasmos de tocador" (Balzac, 2010: 86-88).

Por otra parte, los movimientos románticos que, entre los siglos XVIII y XIX, impregnaron su producción artística y cultural de las aspiraciones de libertad, también entraron en una contradicción que resultó significativa: si bien proclamaban el amor como el verdadero vínculo de la relación entre el hombre y la mujer, sin sujeciones al modelo contractual mercantilizado o a las diferencias de clase social, sublimaron la dependencia entre los amantes y la devoción que se debían recíprocamente.

El modelo de amor romántico recaló en todas las clases sociales. Retomado del Romeo y Julieta (1597) de Shakespeare, morir de amor y por amor, el sacrificio, la traición amorosa o los celos, fueron elevados a mito en todas las formas de expresión artística, y especialmente en la literaria, desde Manon Lescaut (1731) del Abate Prévost a Las penas del joven Werther (1774) de Goethe, o Sentido y sensibilidad (1811) de Jane Austen; Cumbres Borrascosas (1847) de Emily Brontë; Jane Eyre (1847) de Charlotte Brontë; La Dama de las Camelias (1848) de Alexandre Dumas (hijo); Madame Bovary (1856) de Gustave Flaubert; Anna Karénina (1877) de León Tolstói; o Fortunata y Jacinta (1887) de Benito Pérez Galdós, mostraban la raigambre moral que condicionaba a la mujer al modelo patriarcal, y si no se sometía a él ponía en evidencia su culpa como instigadora del pecado original y, consecuentemente, se hacía merecedora del castigo. En una consolidada y extendida cultura judeocristiana, la imagen tuvo tanto éxito que fue resaltada por todas las formas de expresión artística y cultural y trascendió perviviendo en el tiempo: desde la música, el ballet, la ópera, la escultura, la pintura o la foto- 
grafía, o el cine -desde su aparición-, mostraron esos ideales románticos de amor y sacrificio, culpa y condena, con gran éxito entre todas las clases sociales.

En todo caso, el proceso de concienciación sobre las desigualdades sociales que se gesta en la nueva sociedad contemporánea llevará implícito el de la concienciación femenina, y a lo largo del siglo XIX, las mujeres van conformando el movimiento sufragista, más tarde feminista, extendiéndose primero en Reino Unido y EEUU, materializándose en acciones como la estadounidense Declaración de Seneca Falls celebrada en 1848, o el primer debate parlamentario sobre el derecho de las mujeres al sufragio que presentará John Stuart Mill (1806-1873) ante la Cámara de los Comunes inglesa en 1866 y 1867, a partir de las propuestas sufragistas de asociaciones unidas en 1868 en la National Society for Woman's Suffrage (NSWS). Mill, que había cambiado su posicionamiento ideológico conservador por el amor profesado a la que sería su esposa, Harriet Taylor Mill (1807-1858), publicará El sometimiento de las mujeres en 1869, argumentando a favor de la emancipación de las mujeres de las instituciones patriarcales, obteniendo gran repercusión e influencia en la intensificación del sufragismo hacia el movimiento feminista, que iban ampliando sus exigencias igualitarias más allá del derecho al voto (Marín Gómez, 2020).

El feminismo se va consolidando a fines del siglo XIX y principios del $X X$, con gran diversificación de reivindicaciones y acciones sociales exigiendo el reconocimiento de sus derechos de igualdad y cambios sociales estructurales, especialmente en el modelo de familia. La norteamericana Kate Chopin publicaba El despertar (1899), demostrando el conflicto que afectaba a las mujeres entre sus deberes matrimoniales y maternales y su ansia de liberarse de ellos. Igualmente influyentes fueron ejemplos como la Sociedad Fabiana en Inglaterra, que contó entre sus miembros con destacadas feministas y algunas posiciones masculinas a favor de sus reivindicaciones. Escritores como H. G. Wells, Thomas Hardy o George Bernard Shaw participaron en la Liga de Hombres para el Sufragio Femenino, fundada en 1907.

En 1909, H.G.Wells (1866-1946) publicó su novela Ann Veronica, cuya protagonista es una mujer que lucha por sus derechos políticos y libertades personales y aspira a desarrollar al máximo su intelecto en la Universidad, en contra de la voluntad paternal y de las imposiciones morales victorianas (Marín Gómez, 2020). Y en 1928, George Bernard Shaw (1856-1950) publicaba el Manual de socialismo y capitalismo para mujeres inteligentes, en el que, recogiendo los intereses feministas, destacaba la necesidad de la mujer de romper con esas imposiciones morales, sociales y religiosas que reducían su vida al matrimonio y a la maternidad, y que hombres y mujeres tenían los mismos derechos. Para Shaw, una igualdad que podía obtenerse con el socialismo, porque bajo el sistema capitalista: "las mujeres estaban peor que los hombres porque, como el capitalismo convertía al hombre en esclavo, y al pagar a la mujer a través de él la convertía en su esclava, esta se convirtió en la esclava de un esclavo, que es la peor suerte de esclavitud" (Shaw, 2013: 329).

En efecto, las mujeres del recién iniciado siglo XX intentaban propalar un nuevo ideal de mujer alejado de las imposiciones patriarcales y paternalistas. La Nueva Mujer se presentaba con la idea de liberarse del sometimiento al matrimonio y a la familia; aspiraban a poder vivir en soltería, a tener acceso a la educación incluso superior, y al desarrollo de una profesión científica, humanística, artística o cultural; al igual que a la libertad en sus relaciones sexuales. Como el citado Wells, quien tras diversas relaciones matrimoniales y extramatrimoniales, y la publicación de su novela Matrimonio (1912), sobre la convenciones sociales y los celos, conoce en 1913 a Rebecca West (1892-1983), crítica literaria e influyente feminista, escritora y periodista, que en respuesta a la obra de Wells publicará en 1914: Matrimonio indisoluble. La pareja convivirá diez años, con un hijo en común, en una relación abierta que no llegaría al matrimonio. Wells no llegó a divorciarse y West no quiso renunciar a su independencia, anteponiendo su trabajo, y también su fama, a la familia. La cuestión matrimonial no dejó de formar parte de sus debates, y en ese año de 1914, Amber Reeves -que también había sido amante y madre de otra hija de Wells- publicaba A Lady and her Husband. Todos sus argumentos tenían en común los problemas de las relaciones matrimoniales y las condiciones femenina y masculina dentro de la pareja. Y son solo una muestra del cuestionamiento generalizado sobre las relaciones entre hombres y mujeres, en una constante lucha entre el cambio y la permanencia de los modelos tradicionales (Marín Gómez, 2020).

En España, también el feminismo se introdujo en los ámbitos intelectuales, y desde Emilia Pardo Bazán (18511921), cuya obra y posición reivindicativa respeto a los derechos de las mujeres fue públicamente notoria, a Carmen de Burgos (1867-1932) -conocida como Colombine, que en 1927 publicaba La mujer moderna y sus derechos-conteniendo muchos elementos del análisis de género que desarrollaría más tarde Simone de Beauvoir-, entre otras muchas intelectuales, literarias y artistas, propiciaron que, con la proclamación de la Segunda República en 1931, se lograra constitucionalmente la entrada de las mujeres en la política parlamentaria y el derecho al voto femenino, con el impulso decisivo de la diputada Clara Campoamor (1888-1972).

Las guerras mundiales, y la guerra civil en España, paralizaron los avances logrados por el feminismo en cuanto a los derechos de las mujeres, las relaciones de género y los cambios en los modelos de familia, y al finalizar las contiendas hubo un claro retroceso con una restauración de la situación femenina hacía la domesticidad y el cuidado familiar, así como al modelo de familia patriarcal, fortalecido por el paternalismo político (Vázquez de Prada, 2008).

Las masculinidades reforzaron su machismo por la experiencia militar en los conflictos, y los cuestionamientos existencialistas coadyuvaron a reactivarlas, dejando de lado la voluntad femenina de prosperar. Representativa es la novela que en 1953 publicaba el escritor cubano Alejo Carpentier (1904-1980): Los pasos perdidos, en la que el musicólogo protagonista emprende un viaje a un paraíso selvático, guiado por una búsqueda de sí mismo de la que resulta un constante desencuentro. Se mueve en un intenso triángulo amoroso que no es capaz de discernir: la esposa legítima -el matrimonio convencional-; la amante -que le acompaña en su viaje y satisface sus necesidades 
sexuales-, y el encuentro en el paraíso selvático con la nueva amada salvaje y libre, que supone el gran reto para la masculinidad conquistadora.

Esa desubicación del protagonista es significativa "si se mira a la luz de la sexualidad masculina, porque representa la constante imposibilidad de unir dos elementos necesarios para sentirse completo: cuando tiene la inspiración, le falta papel para anotar melodías; cuando lo tiene carece de inspiración". Es probablemente representativa de la identidad masculina desarrollada a lo largo de los siglos XIX y $X X$ frente al avance de las mujeres, constatando las dificultades masculinas para aceptarlo: "la permanente sensación de insuficiencia abruma al protagonista en diferentes ámbitos geográficos. Lo único constante en todos los ambientes es él mismo. Con todo, la obsesión con la falta de algo nunca se transforma en una búsqueda interior"; y es por eso "que el rosario de mujeres no le es suficiente para alterar por mucho tiempo su casi constante sensación de fracaso. Su búsqueda egocéntrica y narcisista, no da fruto porque nunca reconoce en ninguna de las mujeres a un ser igual" (Bilbija, 2004: 35).

El arraigo secular de esas reticencias masculinas contribuyeron a que, a pesar del éxito de El segundo sexo de Beauvoir, publicada en 1949, en el contexto del pensamiento existencialista del momento, el resurgimiento del movimiento feminista no se reactivara hasta los 60', cuando, frente a la bipolarización capitalista-comunista y la expansión irreversible del modelo capitalista, reincidiera la jerarquización de género, pero con unas mujeres que ahora aspiraban a mucho más que la liberación de la domesticidad: el acceso absoluto a la educación en todos los niveles; un empleo y un salario que les permitiera independencia económica; una libertad de decisión en cuanto a la maternidad y el matrimonio, entre otras pretensiones, y eso llevaba implícito no solo la re-concienciación sobre las desigualdades de género, sino a despertar una conciencia histórica y política, que llevará a las mujeres a abordar las cuestiones de género tanto científicamente como personalmente, con el compromiso político, ideológico y social, para alcanzar el reconocimiento de los derechos que históricamente le venían siendo arrebatados y vetados.

Así se encontraron las mujeres, como el protagonista de Los pasos perdidos, en medio de la espesura de una selva paradisíaca de bifurcados, tortuosos y a veces impenetrables caminos, con la dificultad de identificarse y luchar con las permanencias y las rupturas desde la acción y desde el conocimiento, siempre controvertidas porque, como señala Blasco: "asistimos a una ampliación del campo de estudio que, unido al impacto de los procesos culturales ligados a la globalización, está resultando en una producción no solo inabarcable sino también muy heterogénea en el plano teórico. Estas dinámicas de ampliación e internacionalización han contribuido a su vez al cuestionamiento del género como categoría de análisis, tal y como había quedado conceptualizado" (Blasco Herranz, 2020: 144).
3. La historia “¡A la calle!". La conciencia de género, la conciencia histórica y los cambios sociales
"¡A la calle!, que ya es hora de pasearnos a cuerpo
y mostrar que, pues vivimos, anunciamos algo nuevo" Gabriel Celaya, "España en Marcha", Cantos Íberos (1955)

Los versos de Celaya invitando a salir a la calle para anunciar lo nuevo, en la década de 1950, habrían podido guiar el imaginario colectivo que despertó la explosión de acciones sociales reivindicativas a partir de esos años, llevando a la calle a un buen número de personas reclamando una multiplicidad de derechos que seguían viéndose vulnerados. Vulnerados y execrados tanto por los Estados, olvidados de las promesas de unas políticas del bienestar social anteriores y entre las guerras mundiales, absorbidos ahora por la continuidad del belicismo y del colonialismo en políticas geoestratégicas, inmersas en la polarización entre el mundo capitalista estadounidense y el comunista soviético, como por una gran parte de la sociedad cuyas mentalidades habían sido moldeadas desde un secular proceso educativo y cultural eminentemente patriarcal, que había naturalizado las desigualdades sociales, incluidas las de género, como propias de un "estilo de vida", o, como señala Therborn, mejor denominadas "opciones de vida", referidas a aquellas posibilidades ante las que se encontraban los individuos para poder superar, o no, las desigualdades sociales que les afectaban (Therborn, 2015: 90).

En la sociedad de la segunda mitad del siglo XX, devenida del modelo industrial fordista, de las inseguridades de estabilidad económica que había visibilizado el Crack del 29', y de las consecuencias de las guerras mundiales, que habían puesto en entredicho la "civilización" y el "progreso", se había consolidado ese principio de incertidumbre -formulado por Werner Heisenberg en 1927- que parecía "dar base científica al escepticismo especulativo e intuitivo de los intelectuales", sentando las bases de una "cultura del pesimismo" (Fusi Aizpúrua, 1991: 334). Un pesimismo que, en esos 50', llevó a una reinterpretación del existencialismo -representado por Sartre, Beauvoir o Camus, entre otros-, dando lugar a dos vertientes: por una parte, a una concepción del individualismo como guía para comprender la igualdad social como necesaria para el desarrollo personal, y, por otra, la expansión de un proceso de concienciación colectiva de la sociedad civil, y de la desigualdad social que como tal le afectaba históricamente, motivando el estallido de lo que se llamarían nuevos movimientos sociales a partir de la década de 1960, entendidos como motor para alcanzar la libertad y la igualdad absolutas en el marco del reconocimiento de la identidad ciudadana (Riechmann y Fernández Buey, 1995).

Movimientos que alcanzaron dimensiones y repercusiones internacionales, con una multiplicidad de objetivos a reivindicar. $Y$ entre ellos destacó el movimiento feminista, que, como se ha visto, gestó la aparición de un proceso 
historiográfico sobre la cuestión de género, conscientes de que la labor desarrollada por mujeres, y algunos hombres, especialmente desde el siglo XVII hasta principios del XX, desde las ilustradas a las sufragistas, para lograr sus derechos e integración en los espacios público y político -la considerada primera ola feminista (Pérez Garzón, 2011)-, se había visto reiteradamente subvertida a medida que se intentaba avanzar en igualdad entre los sexos, prevaleciendo la referida jerarquía de género, y, por tanto, las relaciones de poder, en la que el hombre seguía ocupando el nivel superior, hasta incluso eclipsar la identidad femenina con la excusa de los conflictos bélicos mundiales.

Pero esa desigualdad de género reforzada tras la segunda guerra mundial encontró a las mujeres en un momento diferente, pues durante los conflictos bélicos mundiales, no solo se habían tenido que hacer cargo de las responsabilidades familiares y domésticas, sino que habían participado igualmente en el trabajo industrial y en los servicios auxiliares, así como en tareas de defensa e incluso en el combate directo, asumiendo una toma de conciencia y unos cambios en las mentalidades mucho más profundos de lo que hasta entonces se había producido. Además, la reconstrucción occidental de posguerra en los 50' hizo necesaria la reestructuración de la mano de obra y del empleo asalariado en diversos sectores económicos, viéndose obligados a conservar o incluir a las mujeres, dando paso a "la idea del trabajo de la mujer como factor de independencia social y de dignidad profesional, por más que se mantuvieron diferencias de tareas por sexo y la discriminación salarial" (Pérez Garzón, 2011: 182).

Frente a la explosión de natalidad desarrollada entre 1946 y 1964, con la llamada generación baby boomers que alcanzó un 18 \% de la población mundial (Díaz-Sarmiento; López y Rocanllo, 2017: 195), hubo también un cambio en la mentalidad femenina respecto a las ideas de maternidad, relaciones sexuales y familia, incluyendo el uso femenino de los métodos anticonceptivos "no solo para tener menos hijos y gozar la familia de mejores condiciones materiales, sino también como factor de liberación individual. La maternidad no se cuestionaba pero la planificación familiar se extendía porque se trataba de que el sexo fuese un derecho al placer y no una servidumbre exclusivamente encaminada a la reproducción" (Pérez Garzón, 2011: 182).

Por otra parte, el reflejo de los Welfare State en los países democráticos proporcionó la posibilidad para las mujeres de alcanzar un mayor nivel educativo en estudios medios y superiores, a lo que se unieron los nuevos modelos de consumo y del hogar, alimentación y comodidades materiales en el domicilio (electrodomésticos, instalaciones e infraestructuras) que aliviaban las tareas domésticas, pero al mismo tiempo que se consolidan las claves del marketing y de la publicidad para la producción y la promoción del consumo en masa, con el papel decisivo de los medios de comunicación en plena expansión, principalmente radio, televisión y cine, encabezados por EEUU. Su proyección logrará expandir el legendario American Dream en el mundo occidental, a través del que se intentaban restablecer los prototipos de mujer, hombre y familia, incluso de infancia, de perfiles de clase media conservadora, retrotraídos al arquetipo burgués ilustrado, para contrarrestar los modelos soviéticos en su propuesta de igualdad de clases, introduciendo las expectativas liberales que promovía el modelo de consumo capitalista.

Una idea para la que, además, la mujer era la destinataria más idónea, como reflejaba Luchino Visconti en Bellisima (1955) -film paradigmático del neorrealismo italiano-, cuya protagonista, Maddalena Cecconi -magistral interpretación de Anna Magnani-, modelo de ama de casa de barrio pobre, y marido obrero, cuyo escaso sueldo intenta completar la esposa ejerciendo de practicante -intrusistapara poder llegar a fin de mes, y que, entusiasmada por la próspera vida mostrada en el cine americano, presenta a su pequeña hija a un casting convocado en los estudios Cinecittà, para seleccionar a la niña protagonista de una película. Maddalena aspira a cambiar radicalmente la vida de su hija y de la familia con el éxito cinematográfico, invirtiendo en ello los ahorros destinados al pago de una nueva vivienda en un barrio menos marginal. Así, Visconti pone a Maddalena en el dilema de perder con sus ahorros su futuro y también la dignidad por sus aspiraciones y expectativas de una vida soñada, que acaba tan frustrada como las aspiraciones de las jóvenes generaciones de los 60'.

Porque, incluso los últimos repuntes de expansión revolucionaria marxista que habían despertado los movimientos representados en el Mayo del 68'francés, poniendo en entredicho valores tradicionales, como "la autoridad familiar, profesoral o patronal", y ensalzando el "prestigio de las ideas de izquierdas heterodoxas -anarquismo, maoísmo, castrismo- alcanzando todo su apogeo" (Sánchez-Prieto, 2001: 110), habían ido adoptando una especie de vuelta a la "normalidad", en la que la Coca-Cola y la Cultura Pop fueron ganando espacios al pensamiento marxista -oponentes que, por ejemplo, desde el cine, en su momento de esplendor como actor crítico social en Europa, el cineasta Jean-Luc Godard había enfrentado en la película Masculin, féminin: 15 faits précis (Francia, 1966)-.

A finales de los 60 ', los obreros y estudiantes, que se habían aliado contra el establishment, acabaron disociando sus objetivos. Para esos jóvenes estudiantes revolucionarios, que en la década de los 80 ' alcanzaban su edad de estabilidad laboral y de formar su propia familia, la sociedad del ocio les ofrecía pasar de "obreros" explotados a "empleados" -ya fuera mal o bien pagados, lo que cambiaba era la condición de prestigio-, en un entorno de Estado de Bienestar que, aunque ya en crisis, había penetrado en las mentalidades diseñando unas políticas sociales de derechos ante el desempleo, la educación y la sanidad, que llevaban implícita una cierta acomodación en el estatus social, respaldado por una inferida seguridad que proporcionaba la existencia de la citada Declaración Universal de Derechos Humanos de 1948.

No obstante, una amplia parte de esa sociedad revolucionaria del 68' había tomado conciencia de la existencia de problemas que requerían de una decisiva reivindicación y participación ciudadana, y fueron transformado el movimiento obrero clásico en una heterogénea acción social que se mostraba en esos otros nuevos movimientos sociales cuyas finalidades se concretaban más visiblemente en el pacifismo, el ecologismo y, una vez más, el feminismo, y que se perfilaron ante situaciones como la guerra de Vietnam (1955-1975); el accidente nuclear de Chernóbil (1986), y la continuada vulneración de los derechos de las 
mujeres y la constatación de las reticencias y las desigualdades que todavía generaba su incorporación al mercado de trabajo y su propia condición femenina (Riechmann y Fernández Rey, 1995).

Es por ello que, como se ha referido anteriormente, a partir de esos años 60' emerge con fuerza la llamada segunda ola feminista (Pérez Garzón, 2011), respaldada especialmente a través del pensamiento de un buen número de mujeres intelectuales y de sus obras fundamentales, entre las que destacaron por su influencia y repercusión: la de la filósofa francesa Simone de Beauvoir y El segundo sexo; y la de dos norteamericanas: Betty Friedan y La mística de la feminidad, y Kate Millett con Política sexual. Sus propuestas se van a ver inmersas en ese contexto histórico de su tiempo, cuando creían que, tras la segunda guerra mundial, se alcanzarían los grandes cambios hacía una sociedad moderna e igualitaria, se encontraron con un mundo masculinizado que se reafirmaba en las luchas políticas y militares en las que las mujeres volvían a estar excluidas y discriminadas. $Y$ en el caso de EEUU, la relegación femenina se unía además a las desigualdades manifiestas que desentrañaba el conflicto racial, con una reactivación del movimiento por los derechos civiles desde 1955, cuando Rosa Parks (1913-2005), activista afroamericana se negara a ceder el asiento a un hombre blanco en el autobús y retirarse a la parte trasera del vehículo destinada a los negros.

Simone de Beauvoir (1908-1986) había empezado su trabajo de investigación sobre la situación de la mujer en la sociedad contemporánea en 1947, ensayo publicado en 1949 y 1950 en dos tomos titulado: El segundo sexo. Un trabajo intelectual que"estaba implicado en las esperanzas y los proyectos de la izquierda; era la época de los grandes relatos de emancipación, de la convicción de que un mundo nuevo era posible, más justo e igualitario" (Näir, 2019: 127). Beauvoir era "hija de su tiempo"; pensaba con las categorías de su época y compartía "los anhelos de sus elecciones ideológicas: mujer pensadora de extrema izquierda, radical, anticonformista, libre, y, sobre todo, convencida, a partir de la segunda guerra mundial, de que la revolución social estaba inscrita en el horizonte de la historia y que iba a estallar en los años venideros" (Näir, 2019: 126).

Por ello, cuando se enfrenta a los cambios que se producen en los años 60' es consciente de que "los interrogantes sobre las relaciones hombre-mujer han cambiado, sin que la dominación organizada estructuralmente por la sociedad masculina haya desaparecido". Razón que le llevará a implicarse activamente en las reivindicaciones feministas, contribuyendo en la lucha sobre el derecho al aborto en los 70', comprometiéndose igualmente "en la defensa de las mujeres iraníes frente al integrismo religioso", sin dejar de defender "causas para cambiar las cosas aquí y ahora, lúcidamente convencida de que la conquista del futuro significaba también el cambio en el presente" (Näir, 2019: 129).

En la misma línea de compromiso intelectual y participación activa se posicionará la norteamericana Betty Friedan (1921-2006), que en 1963 publica La mística de la feminidad, resultado de su estudio de psicología social sobre"el malestar que afectaba a las mujeres estadounidenses de clase media cuyas causas y mecanismos eran todavía desconocidos", y de hecho Friedan lo plantea como "el proble- ma que no tiene nombre", que deviene del "modelo educativo difundido como paradigma imperante" tras la segunda guerra mundial, preconizando "la vuelta de las mujeres al hogar como el sitio donde verdadera y felizmente podrían realizarse". Una situación que suponía una involución y que se convertirá en un fenómeno común a todo occidente experimentando "un retroceso tanto en su valoración social como en sus posibilidades de participación en el espacio público" (Branciforte y Orsi, 2007: 3).

Las repercusiones de su ensayo y sus aspiraciones políticas llevaron a Friedan a cofundar la National Organization for Women (NOW) -acrónimo de doble significado: "Ahora"- en 1966, convirtiéndose en el "grupo feminista progresista con inclinaciones liberales en EEUU" más influyente para desarrollar las ideas sobre la necesidad de la educación y el trabajo de las mujeres como vías para la emancipación, con gran repercusión en viejas y nuevas generaciones de mujeres. Sus propuestas, que coinciden en el tiempo con la "noción de legitimidad creciente de los derechos igualitarios por parte de liberales, hombres y mujeres radicales, y activistas de los derechos civiles- motivaron el surgimiento del feminismo radical de la Segunda Ola, justo en el momento en que sus hijas radicalizadas comenzaron a criticar de manera todavía más áspera la mística del hogar", apoyando la crítica que se hacía desde la izquierda radical a "la maternidad y la familia como instituciones burguesas y patriarcales opresivas". No se negaba la maternidad, pero se planteaba que ésta debía estar basada en la equidad de género, "y sostenían que las instituciones del matrimonio y la familia destruían la individualidad, la comunicación interpersonal y la sexualidad libre" (Bloch, 2013: 96-97). Con su propuestas, Friedan desarrollará tendencias intelectuales e ideológicas que van a llevar a todos los grupos feministas -ya fueran liberales, radicales o académicos- a teorizar y politizar todavía más sobre la cuestión de género (Bloch, 2013).

Igualmente ocurre con Kate Millett (1934-2017), cuya opción se derivó hacia el feminismo radical. Licenciada en Lengua inglesa, en su libro Política sexual, publicado en 1970 , basado en su tesis doctoral defendida en la Universidad de Oxford en 1969, desarrolla un estudio interdisciplinar integrado por la crítica literaria, la antropología, la economía, la historia, la psicología y la sociología. Para Millett "el sexo es una categoría social impregnada de política. La relación de los sexos es política porque es una relación de poder", expresando igualmente "que hasta en las relaciones personales se introducen elementos de poder y de dominación" (López Pardina, 2016: 22). Un análisis que partía del ensayo de Carol Hanisch titulado "Lo personal es político", publicado en la revista Notes From the Second Year: Women's Liberation en 1970, con extraordinaria repercusión en las ideas feministas y en el desarrollo de los estudios e investigación sobre el género.

Según reconocía la propia Simone de Beauvoir daba la impresión que las mujeres estadounidenses habían conseguido más derechos como mujeres porque "más que otras mujeres, las americanas se daban cuenta de las contradicciones entre los progresos de la tecnología y la tradición que confinaba a la mujer a la cocina" (Näir, 2019: 132), sin embargo, las feministas norteamericanas se encontraron ante un controvertido proceso por la Enmienda de Igual- 
dad de Derechos (Equial Rights Amendment -ERA-), estancada desde su propuesta en 1923, fue aprobada por la Cámara en 1970 y por el Senado en 1972, pero necesitaba la ratificación de tres cuartas partes de los Estados (38), según establece la Constitución Federal de Estados Unidos, lo que dio lugar a un enfrentamiento entre el movimiento feminista, liderado entre otras por Gloria Steinem, Betty Friedan, Bella Abzug, o Shirley Chisholm, la primera mujer afroamericana elegida para el Congreso de los Estados Unidos en 1968, y la radical oposición conservadora de la National Federation of Republican Women, liderada por Phyllis Schlafly (1924-2019), cuya campaña STOP ERA y su coalición ERAmerica consiguieron que no se ratificara el $E R A$ en todos los Estados, quedando pendiente de aprobación en 2021, por Estados que todavía no lo han ratificado.

Desde el ámbito político institucional, la ONU también asumió la necesidad de ampliar la integración de la igualdad entre los géneros en sus objetivos, y convocó Conferencias Mundiales sobre la Mujer (Ciudad de México, 1975; Copenhague, 1980; Nairobi, 1985 y Beijing, 1995). La Conferencia de Beijing sería la más transcendental al aprobar por unanimidad la Declaración y la Plataforma de Acción, incorporando los mecanismos de actuación denominados gender mainstreaming o transversalidad de la perspectiva de género, con la intencionalidad de incorporarla en el diseño, ejecución y evaluación de todas las políticas públicas.

Pero en un mundo en el que han ido obteniendo éxitos rotundos historias como las de Love Story (EEUU, Arthur Hiller, 1970), Pretty Woman (EEUU, Garry Marshall, 1990) - Cincuenta sombras de Grey (EEUU, Sam Taylor-Johnson, 2015) en las que las relaciones de género, sexo y la familia muestran arquetipos homéricos y shakespearianos se pone en evidencia que todavía queda mucho por hacer. Pensar que la igualdad de género se ha logrado no es más que un mito, quedan como heridas abiertas las constantes circunstancias que continúan amenazando los derechos humanos en general, y los de las mujeres en particular, como demostraron las dimensiones internacionales que alcanzó la celebración del 8 de marzo de 2018, revitalizada por los movimientos MeToo o LGTBIQ+, entre muchos otros. Derechos que han recogido los Objetivos de Desarrollo Sostenible (ODS), de la Agenda 2030 de la ONU, cuyo número 5 propone el logro de la lgualdad de Género y empoderar a todas las mujeres y las niñas, con las metas específicas de poner fin a la discriminación; eliminar todas las formas de violencia contra la mujer; el matrimonio infantil y la mutilación; el trabajo de cuidados domésticos; la participación plena de la mujer y la igualdad de oportunidades; igualdad de derechos a los recursos económicos; mejorar el uso de la tecnología y el acceso a las tecnologías de la información y la comunicación y aprobar y fortalecer políti-

\footnotetext{
9 La falta de ratificación por número necesario de 38 Estados llevó a la expiración del plazo para su aprobación. Frente al nefasto mandato de Donald Trump (2017-2021) para la igualdad de derechos y la reactivación de movimientos feministas como el MeToo, entre otros, se recuperó su solicitud sin que se haya conseguido en 2021 completar la ratificación por el número necesario de Estados. Salvà, N.: "Las mujeres de EEUU: discriminadas por ley. La serie'Mrs America' revive la lucha, a principios de los 70 , del feminismo estadounidense para la aprobación de un texto legal que reconocía la igualdad y que todavía sigue sin efecto", en www.elperiodico.com, 11/04/2020, https://www.elperiodico.com/ es/cuaderno/20200411/las-mujeres-de-eeuu-discriminadas-por-ley-7923388.
}

cas y leyes para la igualdad y el empoderamiento ${ }^{10}$, frente a las constantes acciones reaccionarias como la violencia de género, que parece asentarse como una lacra estructural; o la vuelta al poder de los talibanes en Afganistán ${ }^{11} ;$ o en Estados Unidos, con la entrada en vigor en Texas de una de las leyes más restrictivas contra el aborto ${ }^{12}$, en lo que parece mantener la milenaria guerra de violencia contra las mujeres (Venegas, Reverte y Venegas, 2018), que no garantiza el progreso en la igualdad entre hombres y mujeres, como viene demostrando la Historia, predisponiéndolo a convertirlo, igual que este ensayo, en una entelequia.

\footnotetext{
10 En 2021, el Ministerio del gobierno español encargado de la Agenda 2030 es el de Derechos Sociales: https://www.agenda2030.gob.es/objetivos/objetivo5. htm

${ }^{11}$ La prensa se ha hecho eco de ello, véase, por ejemplo: Venzalá, Clara R.: “Las mujeres de Afganistán, siempre en la encrucijada: Las afganas siempre lo tuvieron complicado. Los lentos avances en materia de género, la desigualdad entre áreas urbanas y rurales, así como la sospecha de que sus derechos puedan haber sido moneda de cambio en las negociaciones de paz con los talibanes evidencian un pasado, presente y futuro difícil para ellas", El País, 02/09/2021 https://elpais.com/planeta-futuro/2021-09-02/las-mujeres-de-afganistan-siempre-en-la-encrucijada.html

12 Agencia EFE: “Entra en vigor en Texas una de las leyes antiaborto más restrictivas de EEUU: Biden subraya que la norma texana "viola flagrantemente el derecho constitucional" y promete que defenderá el derecho al aborto", Público, 01/09/2021: https://www.publico.es/internacional/entra-vigor-texas-leyesantiaborto.html
} 
AMORÓS PUENTE, A. (2018): "Introducción”, en Poulain de la Barre, De la educación de las damas para la formación del espíritu en las ciencias y en las costumbres. Madrid, Cátedra, pp. 33-42.

BALZAC, Honoré (2010): Mujeres lo bastante ricas. Cáceres, Editorial Periférica.

BEARD, M. (2018): Mujeres y poder. Un manifiesto. Barcelona, Crítica.

BEL BRAVO, Ma A. (2000): La familia en la Historia. Propuestas para su estudio desde la "nueva"historia cultural. Madrid, Ediciones Encuentro.

BILBIJA, Ksenija (2004): "Itinerarios de la masculinidad en Los Pasos Perdidos de Alejo Carpentier y La Conquista del Paraíso de Eliseo Subiela", INTI- Revista de Literatura Hispánica, 59, pp. 25-46.

BLASCO HERRANZ, I. (2020): “Historia y género: líneas de investigación y debates recientes en Europa y Norteamérica", Historia y Memoria, Edición Especial, pp. 143-178. https:/doi.org/10.19053/20275137. nespecial.2020.11584.

BLOCH, A. H. (2013): "Betty Friedan: el trabajo de las mujeres, el liberalismo posterior a la segunda guerra mundial y los orígenes de la liberación femenil en Estados Unidos", Signos Históricos, 30, pp. 64-106.

BRANCIFORTE, L. y ORSI, R. (2007): “De la mística de la feminidad al mito de la belleza". E-archivo Universidad Carlos III (Madrid), en línea: http://e-archivo.uc3m.es/handle/10016/1096/browse?type=author \&order $=$ ASC\&rpp $=20$ \&value $=$ Branciforte $\% 2 C+$ Laura.

CARRERAS ARES, Juan José (2000): Razón de Historia. Estudios de Historiografía. Zaragoza, Marcial Pons.

CHACÓN JIMÉNEZ, F. (2020): “Las familias como definidoras del proceso histórico, circa mitad siglo XVIII-siglo XXI. El ejemplo de España en el contexto europeo", en E. Pastor Seller et al. (eds.), Familias, identidades y cambio social en España y Portugal. Siglos XIX-XXI. Perspectivas comparadas europeas. Pamplona, Thomson Reuters Aranzadi, pp. 31-48.

DÍAZ FREIRE, J. J. (2015): “Presentación”, Ayer, 98 (2), monográfico “Emociones e historia", pp. 13-20.

DÍAZ-SARMIENTO, C.; LÓPEZ-LAMBRAÑO, M. y ROCALLO-LAFONT, L. (2017): “Entendiendo las generaciones: una revisión del concepto, clasificación y características distintivas de los baby boomers, $\mathrm{X}$ y millennials", Revista Clío América, 11 (22), pp. 188-204.

FONTANA, J. (1999): Introducción al estudio de la historia. Barcelona, Crítica.

FONTANA, J. (1992): La historia después del fin de la Historia. Reflexiones acerca de la situación actual de la ciencia histórica. Barcelona, Crítica.

FUKUYAMA, F. (1990): “¿El fin de la Historia?", Claves de la razón práctica, 1, pp. 85-96. Original: "The End of History?", The National Interest, 16 (1989), pp. 3-18.

FUSI AIZPÚRUA, J. P.: "La crisis de la conciencia europea”, en M. Cabrera, S. Juliá y P. Martín Aceña (comps.), Europa en crisis, 1919-1939. Madrid, Editorial Pablo Iglesias.

HARARI, Y. H. (2014): De animales a dioses. Breve historia de la humanidad. Barcelona, Debate.

LERNER, G. (1990): La creación del patriarcado. Barcelona, Crítica.

LÓPEZ PARDINA, T. (2016): "Prólogo a la edición española”, en S. Beauvoir [1949], El segundo sexo. Madrid, Cátedra, pp. 7-34.

MARÍN GÓMEZ, I. (2020): “La contribución del feminismo intelectual a los cambios y permanencias en el modelo de matrimonio y familia burgueses (siglos XIX-XXI)", en E. Pastor Seller et al. (eds.), Familias, identidades y cambio social en España y Portugal. Siglos XIX-XXI. Perspectivas comparadas europeas. Pamplona, Thomson Reuters Aranzadi, pp. 65-82.

MEDINA QUINTANA, S. (2014): “Gerda Lerner: la Historia como compromiso", Asparkía, 25, pp. 225-230.
NAÏR, S. (2019): Acompañando a Simone de Beauvoir. Mujeres, hombres, igualdad. Barcelona, Galaxia-Gutenberg.

PÉREZ GARZÓN, J. S. (2011): Historia del feminismo. Madrid, Los Libros de la Catarata.

PERROT, M. (1995): “Escribir la historia de las mujeres: una experiencia francesa", Ayer, 17, pp. 67-83.

PONTÓN, G. (2017): La lucha por la desigualdad. Una historia del mundo occidental en el siglo XVIII. Barcelona, Pasado \& Presente.

RAMONET, I. (1997): “Crisis de fin de siglo”, en VV.AA., Escenarios de la Globalización. Murcia, Cajamurcia, pp. 15-39.

REBOUL, A.M. (1996): “La mujer y el amor en El diablo cojuelo y Le diable coiteux", Revista de Filología Francesa, 10, pp. 229-242.

SÁNCHEZ-PRIETO, J. Ma (2001): "La historia imposible del Mayo francés", Revista de Estudios Políticos, 112, pp. 109-133.

RIECHMANN, J. y FERNÁNDEZ BUEY, F. (1995): Redes que dan libertad. Introducción a los nuevos movimientos sociales. Barcelona, Paidós.

ROSE, S.O. (2012): ¿Qué es Historia de Género? Madrid, Alianza Editorial.

SANMARTIN, I. (1998): “Evolución de la teoría del «fin de la Historia» de Francis Fukuyama", Memoria y Civilización, 1, pp. 233-245.

SHAW, G. B. (2013): Manual de socialismo y capitalismo para mujeres inteligentes. Barcelona, RBA.

STAROBINSKI, J. (1988): 1789, los emblemas de la razón. Madrid, Taurus.

THERBORN, G. (2015): La desigualdad mata. Madrid, Alianza Editorial.

VALCÁRCEL, A. (2011): “Prólogo”, en J. S. Pérez Garzón, Historia del feminismo. Madrid, Los Libros de la Catarata, pp. 11-13.

VÁZQUEZ DE PRADA, M. (2008): Historia de la familia contemporánea. Principales cambios en los siglos XIX y XX. Madrid, Rialp.

VENEGAS, L.; MARTÍNEZ REVERTE, I. y VENEGAS, M. (2019): La guerra más larga de la Historia. 4.000 años de violencia contra las mujeres. Barcelona, Espasa-Planeta.

VILAR, P. (1997): Pensar históricamente: Reflexiones y recuerdos. Barcelona, Crítica. 